\title{
Gasometric gradients between blood obtained from the pulmonary artery wedge and pulmonary artery positions in pulmonary arterial hypertension
}

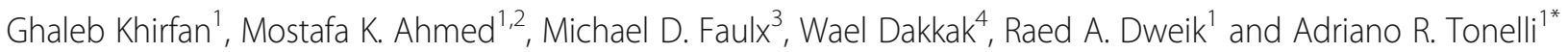

\begin{abstract}
Introduction: Little is known on the pulmonary gradients of oxyhemoglobin, carboxyhemoglobin and methemoglobin in pulmonary arterial hypertension (PAH). We sought to determine these gradients in group $1 \mathrm{PAH}$ and assess their association with disease severity and survival.

Methods: During right heart catheterization (RHC) we obtained blood from pulmonary artery (PA) and pulmonary artery wedge (PAW) positions and used co-oximetry to test their gasometric differences.

Results: We included a total of 130 patients, 65 had group 1 PAH, 40 had pulmonary hypertension (PH) from groups 2-5 and 25 had no PH during RHC. In all groups, PAW blood had higher pH, carboxyhemoglobin and lactate as well as lower $\mathrm{pCO}_{2}$ than PA blood. In group $1 \mathrm{PAH}$ (age $58 \pm 15$ years, $72 \%$ females), methemoglobin in the PAW was lower than in the PA blood $(0.83 \% \pm 0.43$ vs $0.95 \% \pm 0.50, p=0.03)$ and was directly associated with the degree of change in pulmonary vascular resistance $(R=0.35, p=0.02)$ during inhaled nitric oxide test. Oxyhemoglobin in PA (HR (95\%Cl): 0.90 (0.82-0.99), $p=0.04$ ) and PAW (HR (95\%Cl): 0.91 (0.84-0.98), $p=0.003$ ) blood was associated with adjusted survival in PAH.

Conclusions: Marked differences were observed in the gasometric determinations between PAW and PA blood. The pulmonary gradient of methemoglobin was lower in PAH patients compared to controls and a higher PAW blood methemoglobin was associated with a more pronounced pulmonary vascular response to inhaled nitric oxide. Pulmonary artery and PAW oxyhemoglobin tracked with disease severity and survival in PAH.
\end{abstract}

Keywords: Blood gas analysis, Methemoglobin, Pulmonary hypertension

\section{Introduction}

Pulmonary arterial hypertension (PAH) is a condition characterized by progressive narrowing of the small pulmonary arteries that if left untreated leads to right heart failure and death [1]. This pre-capillary involvement results in a distinct hemodynamic profile characterized by a mean pulmonary artery pressure (mPAP) $\geq 25 \mathrm{mmHg}$, pulmonary artery wedge pressure (PAWP) $\leq 15 \mathrm{mmHg}$ and pulmonary vascular resistance $(\mathrm{PVR})>3$ Wood units [2]. During the

\footnotetext{
* Correspondence: tonella@ccforg

1Department of Pulmonary, Allergy and Critical Care Medicine, Respiratory Institute, Cleveland Clinic, 9500 Euclid Avenue A-90, Cleveland, OH 44195, USA

Full list of author information is available at the end of the article
}

last three decades, the understanding of the pathobiology of PAH has markedly improved; however, there remains a need to determine whether certain gasometric alterations play a role in the pathogenesis of $\mathrm{PAH}$.

The lungs oxygenate the blood and remove the carbon dioxide $\left(\mathrm{CO}_{2}\right)$ generated by metabolic processes. It remains unknown how the lungs of patients with $\mathrm{PAH}$ process carboxyhemoglobin $(\mathrm{COHb})$ and methemoglobin (metHb); which are compounds potentially involved in the pathogenesis of the disease [3-6]. Endogenously, carbon monoxide $(\mathrm{CO})$ is produced by the catabolism of heme by heme oxygenase [7]. Carbon monoxide is in part produced in the lungs $[8,9]$ where it may act as a pulmonary vasodilator [10]. Methemoglobin results from the

(C) The Author(s). 2019 Open Access This article is distributed under the terms of the Creative Commons Attribution 4.0 International License (http://creativecommons.org/licenses/by/4.0/), which permits unrestricted use, distribution, and 
oxidation of the hemoglobin iron to a ferric $\left(\mathrm{Fe}^{+++}\right)$state, a reaction that occurs when oxyhemoglobin reacts with nitric oxide (NO) [11]; therefore levels of metHb may track with levels of NO, a potent vasodilator implicated in the pathogenesis of PAH [12].

Transpulmonary gradients are traditionally measured between pulmonary artery (PA) (mixed venous) and systemic arterial blood (e.g. radial artery) [13-18]; however, arterial blood may be affected by right-to-left shunts from the Thebesian veins and potential metabolic processes between the left heart and the arterial sampling site. An approach to prevent these problems is to obtain blood from the pulmonary artery wedge (PAW) position (Fig. 1), indeed PAW blood has been studied in a variety of diseases [19-21]. Notably, PAW blood can be obtained at the time of right heart catheterization (RHC) without the need for an arterial puncture. In our practice we routinely obtain PA blood (mixed venous) for indirect/direct Fick cardiac output calculation and PAW blood to support an adequate PAW measurement [22]. Given that there is limited information on the pulmonary gradients of certain gases in PAH, we used co-oximetry to test the differences between blood obtained at the PA and PAW positions. We hypothesize that patients with $\mathrm{PAH}$ (group 1) have derangements in $\mathrm{COHb}$ and metHb as a result of defects in the NO pathway. We further hypothesize that $\mathrm{COHb}$ and metHb gradients may not only provide an insight on the metabolic processes that occur in the lungs of PAH patients but may be associated with disease severity, inhaled NO response and survival.

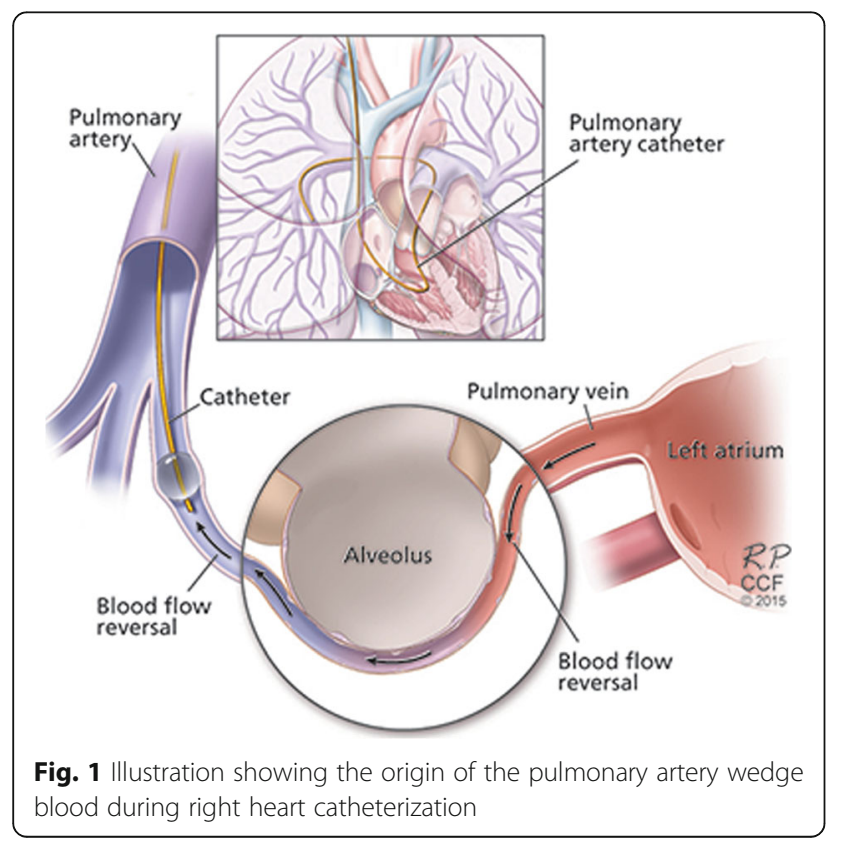

\section{Materials and methods}

\section{Subjects and study design}

This cross-sectional study was approved by the Cleveland Clinic institutional review board (study number: 06-245 and 14-1069). Written informed consent was waived given the retrospective nature of the study. We included consecutive patients who underwent RHC either to a) diagnose pulmonary hypertension $(\mathrm{PH})$ or $\mathrm{b}$ ) manage patients with prior diagnosis of $\mathrm{PH}$. Right heart catheterizations were performed between December 2012 and April 2015.

We carefully assessed each patient to determine the etiology of PH based on the Fifth World Symposium classification [23]. Group $1 \mathrm{PH}$ includes the idiopathic and heritable forms, $\mathrm{PH}$ associated with drugs, toxins, connective tissue and congenital heart diseases, portal hypertension, HIV infection and schistosomiasis. Group 2, 3, 4 and 5 includes $\mathrm{PH}$ due to left heart disease, lung disease/hypoxia, chronic thromboembolic disease and multifactorial mechanisms, respectively. For the purpose of this study, patients were divided into three groups: a) patients with $\mathrm{PAH}$ (PH group 1), 2) patients with $\mathrm{PH}$ groups $2-5$, and 3 ) age- and gender-matched subjects without evidence of resting $\mathrm{PH}$ on RHC (mPAP $<25 \mathrm{mmHg}$ ). Patients without PH underwent RHC due to elevated right ventricular systolic pressure on echocardiography. Patients were excluded $(n=50)$ if the PAW blood could not be obtained during RHC or if it showed an $\mathrm{SO}_{2}<90 \%$, suggestive of an inadequate balloon wedging with leakage of deoxygenated blood from the proximal (before the balloon) to the distal (after the balloon) aspect of the PA catheter.

\section{Right heart catheterization}

Subjects underwent RHC in the outpatient setting by a single operator (A.R.T.). All RHC were done under local anesthesia using $5 \mathrm{~mL}$ of $2 \%$ lidocaine. We continued or started oxygen $\left(\mathrm{O}_{2}\right)$ supplementation in patients in whom the resting pulse oxygen saturation $\left(\mathrm{SpO}_{2}\right)$ was $<90 \%$. We maintained the same $\mathrm{O}_{2}$ flow during all the study measurements. In the supine position and with the transducer located in the mid-thoracic line (4th intercostal space), we measured the right atrial (RA) pressure, mean PAP and PAWP at end-expiration. We determined cardiac output (CO) by thermodilution. We calculated the cardiac index (CO / body surface area), the transpulmonary pressure gradient (TPG: mean PAP - PAWP), diastolic pulmonary gradient (DPG: diastolic PAP - PAWP) and PVR (TPG / CO). When appropriate, we performed a pulmonary vasodilator challenge using inhaled NO at $40 \mathrm{ppm}$ for $5 \mathrm{~min}$ [24].

\section{Laboratory determinations}

Pulmonary artery and PAW blood were obtained immediately after fluoroscopic site confirmation and obtaining an adequate waveform. The tip of the pulmonary artery catheter was located in West zone 3 [25]. Ten $\mathrm{mL}$ of blood 
were discarded from each site before a sample was collected in a blood gas syringe. Blood gas samples were immediately analyzed using the ABL 800 Flex analyzer (Radiometer, Copenhagen, Denmark) which uses cooximetry and provide determinations of $\mathrm{COHb}$, metHb, $\mathrm{Hb}$ and lactate.

\section{Other measurements}

We collected data regarding demographics, use of PAH-specific medications and smoking status (current smoker was defined as a person who smoked tobacco in the last 30 days). We determined the severity of $\mathrm{PH}$ by using the New York Heart Association (NYHA) functional class, plasma $\mathrm{N}$ - terminal pro-B type natriuretic peptide (NT-proBNP), distance walked in the six-minute walk test (6MWD), RV size and function on echocardiography and hemodynamic determinations during RHC. Right ventricular function was determined both subjectively by visual inspection and objectively by the tricuspid annular plane systolic excursion (TAPSE) [26]. We also recorded the diffusion lung capacity for carbon monoxide corrected for $\mathrm{Hb}$ (DLCOc) [27].

\section{Statistical analysis}

Continuous data are presented as mean \pm standard deviation (SD) or median (interquartile range (IQR)) as appropriate. Categorical data are summarized as discrete values and percentages (n (\%)). Continuous and categorical variables were compared across the groups using analysis of variance (ANOVA) and Chi-square, respectively. Paired data were contrasted with paired $t$ test or Friedman test as appropriate. Associations were tested using the Pearson correlation test. Survival analysis was performed with Cox proportional hazards model adjusted by age, gender and other pre-specified variables. The starting point for the survival analyses was the date of the gasometric determinations. Patients were censored at the time of lung transplantation and followed until death or end of the study in January 2018. Cox proportional hazards model results are expressed as hazard ratios (HR) with the corresponding 95\% confidence intervals (CI). All $p$ values are two-tailed and a value of $<0.05$ was considered significant. The statistical analyses were performed using the statistical package IBM SPSS, version 20 (IBM; Armonk, New York) and MedCalc, version 14.12.0 (Ostend, Belgium).

\section{Results}

\section{Baseline characteristics}

We included a total of 130 patients, of whom 65 had group $1 \mathrm{PAH}, 40$ had PH from groups $2-5$ and 25 had no PH during RHC. Of the patients with PAH, 38 (58\%) had idiopathic or heritable PAH, 17 (26\%) had PAH associated with connective tissue diseases, 5 (8\%) had porto-pulmonary hypertension and 5 (8\%) had PAH due to other etiologies. Patients with non-group $1 \mathrm{PH}$ belonged to $\mathrm{PH}$ groups $2(n=20$, $50 \%), 3(n=10,25 \%), 4(n=5,12.5 \%)$ and $5(\mathrm{n}=5,12.5 \%)$. All patients without $\mathrm{PH}(n=25,19 \%)$ had an elevated RVSP $(\geq 40 \mathrm{mmHg}$ ) and associated diseases such as scleroderma, cirrhosis, interstitial lung disease, obstructive sleep apnea or suggestion of left ventricular diastolic dysfunction by echocardiogram.

Of the patients with PAH, 18 (28\%), 15 (23\%), 20 (31\%) and $12(19 \%)$ were on none, 1, 2, and 3 PAH-specific therapies, respectively. These $\mathrm{PAH}$-specific therapies were phosphodiesterase- 5 inhibitors $(n=39,60 \%)$, endothelin receptor antagonists $(n=25,39 \%)$, soluble guanylate cyclase stimulator $(n=1,2 \%)$, and prostacyclin analogues $(n=26$, $40 \%$ ). Baseline characteristics of the three groups of patients are shown in Table 1.

\section{Comparison of PAW and PA blood in patients with group $1 \mathrm{PAH}$}

We observed significant differences between the PAW and PA blood in PAH patients. PAW blood had higher $\mathrm{pH}, \mathrm{COHb}$ and lactate as well as lower $\mathrm{pCO}_{2}$, bicarbonate and metHb when compared to the $\mathrm{PA}$ blood (Table 2).

\section{Comparison of PAW and PA blood gradients among study groups}

A comparison among the three study groups (group 1 $\mathrm{PAH}$, non-group $1 \mathrm{PH}$ and no $\mathrm{PH}$ ) showed that the $\mathrm{pH}$ increase in the PAW compared to the PA blood was more pronounced in group $1 \mathrm{PAH}$ patients (Table 3). We also noted that the metHb was lower in the PAW relative to $\mathrm{PA}$ blood in patients with $\mathrm{PH}$ (group $1 \mathrm{PAH}$ and non-group $1 \mathrm{PH}$ ) compared to individuals without $\mathrm{PH}$ (Table 3). In fact, in individuals without $\mathrm{PH}$, metHb was higher in the PAW than in the PA blood (mean $(95 \% \mathrm{CI})$ difference: $0.12(+0.01,+0.23), p=0.04)$.

\section{Association between blood gases, gradients and disease severity in group $1 \mathrm{PAH}$ patients}

The gradient of $\mathrm{O}_{2} \mathrm{Hb}$ between PAW and PA was directly associated with RA pressure (R: 0.34, $p=0.006$ ), PVR (R: $0.35, p=0.006)$ and NT-proBNP (R: $0.36, p=0.03)$ and inversely associated with $\mathrm{CI}(\mathrm{R}:-0.43, p<0.001)$ and TAPSE (R: $-0.32, p=0.013)$. Other gasometric gradients were not significantly associated with markers of disease severity.

\section{Response to inhaled NO challenge and gasometric determinations in group $1 \mathrm{PAH}$ patients}

In group 1 PAH patients: the PVR decreased a mean of $16.3 \% \pm 16.9 \%(n=45)$. The percentage drop in PVR was inversely associated with $\mathrm{Hb}(R=-0.34, p=0.02)$ and directly associated with metHb $(R=0.35, p=0.02)$ and $\mathrm{O}_{2} \mathrm{Hb}(R=0.321, p=0.03)$ in the PAW blood. 
Table 1 Baseline patient characteristics

\begin{tabular}{|c|c|c|c|c|}
\hline Variable & $\begin{array}{l}\text { Group } 1 \text { pulmonary arterial } \\
\text { hypertension }\end{array}$ & $\begin{array}{l}\text { Groups } 2-5 \text { pulmonary } \\
\text { hypertension }\end{array}$ & $\begin{array}{l}\text { Control } \\
\text { group }\end{array}$ & $\begin{array}{l}\text { P (ANOVA / Chi } \\
\text { square) }\end{array}$ \\
\hline n(\%) & $65(50.0)$ & $40(30.8)$ & $25(19.2)$ & \\
\hline Age (years) & $58 \pm 15$ & $59 \pm 20$ & $54 \pm 20$ & 0.52 \\
\hline Female gender, n (\%) & $47(72)$ & $22(55)$ & $15(60)$ & 0.17 \\
\hline \multicolumn{5}{|l|}{ NYHA functional class, n (\%) } \\
\hline । & $5(8)$ & $4(10)$ & $6(24)$ & 0.14 \\
\hline ॥ & $26(40)$ & $10(25)$ & $9(36)$ & \\
\hline$\|$ & $31(48)$ & $22(55)$ & $10(40)$ & \\
\hline IV & $3(5)$ & $4(10)$ & $0(0)$ & \\
\hline Supplemental $\mathrm{O}_{2}, \mathrm{n}(\%)$ & $29(45)$ & $21(53)$ & $6(24)$ & 0.07 \\
\hline $\begin{array}{l}\mathrm{FiO}_{2} \text { in patients on supplemental } \mathrm{O}_{2} \\
(\%)\end{array}$ & $42 \pm 22$ & $35 \pm 16$ & $29 \pm 3$ & 0.21 \\
\hline NT-proBNP (pg/mL) & $2084 \pm 3247$ & $2087 \pm 2737$ & $180 \pm 153$ & 0.06 \\
\hline 6MWD (m) & $310 \pm 129$ & $317 \pm 106$ & $343 \pm 130$ & 0.61 \\
\hline DLCOc (\% predicted) & $54 \pm 15$ & $51 \pm 28$ & $60 \pm 26$ & 0.43 \\
\hline \multicolumn{5}{|l|}{ Echocardiography } \\
\hline TAPSE (cm) & $1.90 \pm 0.62$ & $1.81 \pm 0.62$ & $2.68 \pm 0.80$ & 0.45 \\
\hline RVSP (mm Hg) & $73 \pm 26$ & $63 \pm 22$ & $50 \pm 18$ & 0.001 \\
\hline \multicolumn{5}{|l|}{$\mathrm{RHC}$} \\
\hline RA pressure (mmHg) & $8 \pm 6$ & $9 \pm 5$ & $4 \pm 3$ & 0.001 \\
\hline mPAP $(\mathrm{mmHg})$ & $42 \pm 14$ & $37 \pm 10$ & $17 \pm 5$ & $<0.001$ \\
\hline PAWP (mmHg) & $10 \pm 5$ & $15 \pm 6$ & $8 \pm 3$ & $<0.001$ \\
\hline TPG (mmHg) & $32 \pm 13$ & $23 \pm 10$ & $9 \pm 3$ & $<0.001$ \\
\hline $\mathrm{Cl}\left(\mathrm{L} / \mathrm{min} / \mathrm{m}^{2}\right)$ & $3.0 \pm 0.9$ & $2.7 \pm 0.8$ & $3.2 \pm 0.7$ & 0.06 \\
\hline PVR (Wood units) & $6.7 \pm 4.2$ & $5.0 \pm 3.5$ & $1.5 \pm 0.8$ & $<0.001$ \\
\hline \multicolumn{5}{|l|}{ Gasometric determinations (PA) } \\
\hline $\mathrm{pH}$ & $7.41 \pm 0.03$ & $7.39 \pm 0.04$ & $7.40 \pm 0.03$ & 0.06 \\
\hline $\mathrm{pCO}_{2}(\mathrm{mmHg})$ & $41.8 \pm 5.7$ & $47.7 \pm 8.5$ & $44.6 \pm 4.6$ & $<0.001$ \\
\hline $\mathrm{SO}_{2}(\%)$ & $68.1 \pm 7.6$ & $66.6 \pm 9.7$ & $72.4 \pm 5.9$ & 0.02 \\
\hline $\mathrm{COHb}(\%)$ & $1.6 \pm 1.1$ & $1.6 \pm 0.9$ & $1.4 \pm 1.0$ & 0.68 \\
\hline metHb (\%) & $1.0 \pm 0.5$ & $0.9 \pm 0.4$ & $0.8 \pm 0.4$ & 0.22 \\
\hline Lactic acid (mmoL/L) & $0.8 \pm 0.4$ & $1.1 \pm 0.5$ & $1.0 \pm 0.4$ & 0.008 \\
\hline \multicolumn{5}{|l|}{ Gasometric determinations (PAW) } \\
\hline $\mathrm{pH}$ & $7.54 \pm 0.08$ & $7.49 \pm 0.10$ & $7.49 \pm 0.08$ & 0.02 \\
\hline $\mathrm{pCO}_{2}(\mathrm{mmHg})$ & $27.1 \pm 8.2$ & $34.0 \pm 10.6$ & $32.3 \pm 7.4$ & 0.001 \\
\hline $\mathrm{SO}_{2}(\%)$ & $93.6 \pm 5.4$ & $92.0 \pm 7.0$ & $93.4 \pm 3.6$ & 0.38 \\
\hline $\mathrm{COHb}(\%)$ & $1.8 \pm 1.2$ & $1.7 \pm 1.1$ & $1.6 \pm 1.0$ & 0.88 \\
\hline metHb (\%) & $0.8 \pm 0.4$ & $0.8 \pm 0.4$ & $0.9 \pm 0.4$ & 0.84 \\
\hline Lactic acid (mmoL/L) & $0.9 \pm 0.4$ & $1.2 \pm 0.6$ & $1.1 \pm 0.5$ & 0.04 \\
\hline
\end{tabular}

Definition of Abbreviations: $\mathrm{COHb}$ : carboxyhemoglobin, $\mathrm{Cl}$ : cardiac index, $\mathrm{DLCOC}$ : diffusion lung capacity for carbon monoxide corrected for hemoglobin, $\mathrm{FiO}_{2}$ : fraction of inspired oxygen, metHb: methemoglobin, $m P A P$ : mean pulmonary artery pressure, NT-proBNP: N-terminal pro-B type natriuretic peptide, NYHA: New York Heart Association, PA: pulmonary artery, PAW: pulmonary artery wedge, PAWP: pulmonary artery wedge pressure, $p C O 2$ : partial pressure of carbon dioxide, PVR: pulmonary vascular resistance, $R A$ : right atrial, $R H C$ : right heart catheterization, $R V S P$ : right ventricular systolic pressure, $\mathrm{SO}_{2}$ :oxygen saturation, TAPSE: tricuspid annular plane systolic excursion, TPG: transpulmonary pressure gradient, 6MWD: distance walked in six-minute walk test

Data are expressed as mean \pm SD or $n(\%)$ 
Table 2 Comparison of pulmonary artery wedge and mixed venous blood in pulmonary arterial hypertension patients $(n=63)$

\begin{tabular}{|c|c|c|c|c|c|}
\hline Variable & Pulmonary artery wedge blood & Mixed venous blood & Mean difference & $95 \% \mathrm{Cl}$ of the difference & $P$ (paired T test) \\
\hline $\mathrm{pH}$ & $7.53 \pm 0.08$ & $7.40 \pm 0.03$ & 0.13 & 0.11 to 0.15 & $<0.001$ \\
\hline $\mathrm{pCO}_{2}(\mathrm{mmHg})$ & $27.1 \pm 8.2$ & $41.9 \pm 5.7$ & -14.80 & -16.42 to -13.10 & $<0.001$ \\
\hline $\mathrm{pO}_{2}(\mathrm{mmHg})$ & $104.4 \pm 53.5$ & $39.6 \pm 4.7$ & 64.85 & 51.40 to 78.30 & $<0.001$ \\
\hline $\mathrm{pO}_{2}{ }^{\mathrm{a}}(\mathrm{mmHg})$ & $82.5 \pm 24.9$ & $40.1 \pm 4.8$ & 42.48 & 38.01 to 50.96 & $<0.001$ \\
\hline $\mathrm{HCO}_{3^{-}}(\mathrm{mmoL} / \mathrm{L})$ & $22.3 \pm 4.0$ & $25.7 \pm 3.3$ & -3.39 & -3.83 to -2.96 & $<0.001$ \\
\hline $\mathrm{O}_{2} \mathrm{Hb}(\%)$ & $93.6 \pm 5.4$ & $68.3 \pm 7.3$ & 25.28 & 22.95 to 27.61 & $<0.001$ \\
\hline $\mathrm{O}_{2} \mathrm{Hb}^{\mathrm{a}}(\%)$ & $92.7 \pm 6.5$ & $70.5 \pm 6.3$ & 22.20 & 19.11 to 25.28 & $<0.001$ \\
\hline $\mathrm{COHb}(\%)$ & $1.76 \pm 1.18$ & $1.59 \pm 1.1$ & 0.16 & 0.06 to 0.26 & 0.002 \\
\hline $\mathrm{COHb}^{\mathrm{b}}(\%)$ & $1.52 \pm 0.79$ & $1.33 \pm 0.61$ & 0.16 & 0.07 to 0.24 & $<0.001$ \\
\hline metHb (\%) & $0.83 \pm 0.43$ & $0.95 \pm 0.50$ & -0.12 & -0.23 to -0.01 & 0.03 \\
\hline $\mathrm{Hb}(\mathrm{g} / \mathrm{dL})$ & $12.7 \pm 2.4$ & $12.8 \pm 2.3$ & -0.11 & -0.29 to +0.07 & 0.24 \\
\hline Lactate (mmoL/L) & $0.94 \pm 0.35$ & $0.82 \pm 0.36$ & 0.12 & 0.08 to 0.15 & $<0.001$ \\
\hline
\end{tabular}

Definition of Abbreviations: $\mathrm{Cl}$ : confidence interval, $\mathrm{COHb}$ : carboxyhemoglobin, $\mathrm{Hb}$ : hemoglobin, $\mathrm{HCO}_{3}$ :: bicarbonate, metHb: methemoglobin, $\mathrm{O}_{2} \mathrm{Hb}_{\text {: oxyhemoglobin, }}$ $p \mathrm{CO}_{2}$ : partial pressure of carbon dioxide, $\mathrm{pO}_{2}$ : partial pressure of oxygen

Data are expressed as mean \pm SD

aPatients not on Oxygen supplementation $(n=36)$

${ }^{b}$ nonsmokers patients only $(n=60)$

\section{Relationship between blood determinations, gradients and survival in $\mathrm{PH}$ patients}

The median (IQR) follow-up for patients with type 1 PAH was 41 (22-51) months, with a 2-year survival of $78 \%$. When adjusted for age and gender, variables associated with mortality in group $1 \mathrm{PAH}$ included: $\mathrm{PA} \mathrm{O}_{2} \mathrm{Hb}$ (HR (95\%CI): $0.87(0.81-0.94), p=0.001)$ and PAW $\mathrm{O}_{2} \mathrm{Hb}$ (HR (95\%CI): 0.93 (0.87-0.98), $\left.p=0.01\right)$. Pulmonary artery $\mathrm{O}_{2} \mathrm{Hb}$ was associated with mortality even when adjusted by supplemental oxygen therapy (HR (95\%CI): 0.89 (0.82-0.96), $p=0.003)$ and adding PVR, 6MWD and number of PAH-specific therapies (HR (95\%CI):0.90 (0.82-0.99), $p=0.04)$. Pulmonary artery wedge $\mathrm{O}_{2} \mathrm{Hb}$ continued to be a significant predictor when adjusted by supplemental oxygen therapy (HR (95\%CI): 0.89 (0.83-0.96), $p=0.001), \quad \mathrm{PA} \quad \mathrm{O}_{2} \mathrm{Hb}$ (HR (95\%CI): 0.88 (0.82-0.95), $p=0.001)$, and adding PVR, 6MWD and number of PAH-specific therapies (HR

Table 3 Differences between pulmonary artery wedge and mixed venous blood in the three groups of patients

\begin{tabular}{|c|c|c|c|c|}
\hline Variable & Group 1 pulmonary arterial hypertension & Groups 2-5 pulmonary hypertension & Control group & P (ANOVA / Chi square) \\
\hline n (\%) & $65(50.0)$ & $40(30.8)$ & $25(19.2)$ & \\
\hline $\mathrm{pH}$ & $0.13 \pm 0.07$ & $0.10 \pm 0.09$ & $0.09 \pm 0.06$ & 0.05 \\
\hline $\mathrm{pCO}_{2}(\mathrm{mmHg})$ & $-14.7 \pm 6.6$ & $-14.2 \pm 8.0$ & $-12 \pm 6.0$ & 0.34 \\
\hline $\mathrm{pO}_{2}(\mathrm{mmHg})$ & $64.9 \pm 53.4$ & $58.0 \pm 47.4$ & $42.7 \pm 27.0$ & 0.14 \\
\hline $\mathrm{pO}_{2}{ }^{\mathrm{a}}(\mathrm{mmHg})$ & $42.5 \pm 24.7$ & $36.4 \pm 21.3$ & $40.9 \pm 26.5$ & 0.70 \\
\hline $\mathrm{HCO}_{3^{-}}-(\mathrm{mmoL} / \mathrm{L})$ & $-3.4 \pm 1.7$ & $-3.0 \pm 1.4$ & $-2.9 \pm 1.3$ & 0.33 \\
\hline $\mathrm{O}_{2} \mathrm{Hb}(\%)$ & $25.3 \pm 9.3$ & $23.7 \pm 9.6$ & $21.0 \pm 6.3$ & 0.12 \\
\hline $\mathrm{O}_{2} \mathrm{Hb}^{\mathrm{a}}(\%)$ & $22.2 \pm 9.0$ & $25.1 \pm 6.7$ & $21.9 \pm 6.1$ & 0.39 \\
\hline $\mathrm{COHb}(\%)$ & $0.16 \pm 0.40$ & $0.09 \pm 0.41$ & $0.21 \pm 0.53$ & 0.55 \\
\hline $\mathrm{COHb}^{\mathrm{b}}(\%)$ & $0.17 \pm 0.41$ & $0.09 \pm 0.42$ & $0.22 \pm 0.56$ & 0.55 \\
\hline metHb (\%) & $-0.12 \pm 0.42$ & $-0.11 \pm 0.43$ & $0.12 \pm 0.27$ & 0.04 \\
\hline $\mathrm{Hb}(\mathrm{g} / \mathrm{dL})$ & $-0.11 \pm 0.74$ & $-0.19 \pm 0.50$ & $0.10 \pm 0.61$ & 0.20 \\
\hline Lactate (mmoL/L) & $0.12 \pm 0.13$ & $0.10 \pm 0.14$ & $0.06 \pm 0.08$ & 0.12 \\
\hline
\end{tabular}

Definition of Abbreviations: $\mathrm{Cl}$ : confidence interval, $\mathrm{COHb}$ : carboxyhemoglobin, $\mathrm{Hb}$ : hemoglobin, $\mathrm{HCO}_{3}$ :- bicarbonate, metHb: methemoglobin, $\mathrm{O}_{2} \mathrm{Hb}_{\text {: oxyhemoglobin, }}$ $p \mathrm{CO}_{2}$ : partial pressure of carbon dioxide, $\mathrm{pO}_{2}$ : partial pressure of oxygen

Data are expressed as mean \pm SD

apatients not on Oxygen supplementation

${ }^{b}$ nonsmokers patients only 
(95\%CI):0.91 (0.84-0.98), $p=0.003)$. Methemoglobin or $\mathrm{COHb}$ levels measured in the PA or PAW, or their pulmonary gradients, did not predict survival.

\section{Discussion}

In the present study we reported results on gasometric gradients between PAW and PA blood and compared findings in patients with group $1 \mathrm{PAH}, \mathrm{PH}$ groups $2-5$ and age- and gender-matched disease controls. In all groups, we noted that the PAW blood showed higher $\mathrm{pH}, \mathrm{COHb}$ and lactate compared to the PA blood. Interestingly, the level of metHb was lower in PAW blood than in PA blood in patients with $\mathrm{PH}$, in contrast to higher levels in the PAW blood in patients without PH. In patients with group $1 \mathrm{PAH}$, we noted that a higher $\mathrm{PAW}$ metHb was associated with a more pronounced PVR drop during inhaled nitric oxide challenge. In patients with group $1 \mathrm{PAH}$, a lower PA and $\mathrm{PAW} \mathrm{O}_{2} \mathrm{Hb}$ levels were independently associated with worse survival.

As shown by others $[19,20]$, the $\mathrm{pH}$ was higher in the PAW blood compared to the PA blood, in association with a lower $\mathrm{pCO}_{2}$. This $\mathrm{pH}$ gradient was more pronounced in patients with $\mathrm{PAH}$ than the other 2 groups of patients. Patients with PAH tend to have lower arterial $\mathrm{pCO}_{2}[28,29]$ given an increase in the respiratory drive, an effect that becomes more evident in the PAW blood. Interestingly, the levels of lactate were higher in the PAW than PA blood suggesting lung production, as seen in other diseases such as acute respiratory distress syndrome $[14,30,31]$. We speculate that the differences in PAW blood are due to a) double lung passage of blood, initially from the PA through the alveolar capillaries and pulmonary veins to the left atrium, and then backwards from the left atrium through the pulmonary veins and alveolar capillaries to the PA catheter, leading to longer exposure to alveolar gas and intensification of the lung processes (Fig. 1) and/or b) prolonged exposure of the PAW blood to alveolar gases, given the temporal immobility of blood in a functional portion of the lung.

Nitric oxide is a potent vasodilator [32] that plays an important role in the pathogenesis of $\mathrm{PH}$ [12]. The reaction with $\mathrm{O}_{2} \mathrm{Hb}$ is one of the catabolic pathways for NO, a process that generates nitrate and metHb [33]. Naples et al. showed that venous metHb correlated with the levels of NO in the plasma of asthmatic patients [34]. In our study, we showed that blood metHb levels are lower in the PAW compared to PA position in PH patients; in contrast, we found higher levels of metHb in PAW position in patients without $\mathrm{PH}$. These findings insinuate a reduced production or an enhanced metabolism of metHb in the lung of $\mathrm{PH}$ patients. Interestingly, in $\mathrm{PAH}$ patients, a higher metHb in PAW blood was associated with a more pronounced decline in PVR during inhaled NO challenge, suggesting a greater diffusion of $\mathrm{NO}$, a healthier pulmonary vasculature and/or an earlier stage of the disease in these patients. Further investigations may determine whether the level of metHb in the PAW position is associated with the response to $\mathrm{PH}$-medications that target the nitric oxide pathway.

Carboxyhemoglobin is produced endogenously during the oxidation of heme compounds by heme oxygenase [35]. The carbon monoxide released from this catabolic reaction has vasodilatory [36], anti-inflammatory [37] and anti-proliferative properties [4]. Hypoxia transiently increases expression of heme oxygenase $[38,39]$. The increased expression of heme oxygenase prevented the development of $\mathrm{PH}$ induced by hypoxia $[38,39]$ a mechanism that may involve the antiproliferative action of carbon monoxide [39]. In the present study, we found that $\mathrm{COHb}$ is higher in the PAW compared to PA blood in all groups of patients, suggesting pulmonary production and systemic metabolism of carbon monoxide. A finding consistent with prior studies which showed positive arteriovenous $\mathrm{COHb}$ difference, with higher $\mathrm{COHb}$ in arterial compared to venous blood [8,34, 40].

Analysis of survival in group $1 \mathrm{PAH}$ patients showed that PA and PAW $\mathrm{O}_{2} \mathrm{Hb}$ adjusted by age, gender, use of supplemental oxygen, PVR and 6MWD are independent predictors of long-term survival. The association between $\mathrm{PA} \mathrm{O}_{2} \mathrm{Hb}$ and survival was expected given previous research [41, 42]. The association between PAW blood $\mathrm{O}_{2} \mathrm{Hb}$ and survival is novel and consistent with our prior study showing that hypoxemia (determined by pulse oximetry) in patients with idiopathic and heritable $\mathrm{PAH}$ is associated with worse survival [43].

Our study has limitations: a) retrospective analysis, b) even though the gasometric differences of metHb are small and might not be clinically significant, they provide an insight on the complex physiological processes involving nitric oxide and c) although patients had a detailed smoking history, surreptitious smoking or other environmental exposure that increased carbon monoxide could not be ruled out. Smoking may affect the pulmonary endothelium, leading to pulmonary vascular remodeling and $\mathrm{PH}$, even in the absence of hypoxemia and destructive emphysematous lung disease [44-48]. Despite these limitations, our study is the first to assess the gasometric gradients between PAW and PA blood in patients with PAH.

\section{Conclusions}

Pulmonary artery wedge blood samples had higher $\mathrm{pH}$ and lower $\mathrm{pCO}_{2}$ than PA, suggesting that PAW blood was exposed to alveolar gas for a longer period of time. Methemoglobin levels were lower in the PAW than PA blood in patients with $\mathrm{PAH}$ and a higher PAW metHb was associated with a more pronounced pulmonary vascular response to inhaled NO. Pulmonary artery and $\mathrm{PAW} \mathrm{O}_{2} \mathrm{Hb}$ tracked with disease severity and survival in PAH patients. 


\section{Funding}

A.R.T is supported by NIH grant \# R01HL130307. M.K.A was supported by the Egyptian Ministry of Higher Education and Scientific Research Scholarship program grant.

\section{Availability of data and materials}

All data generated or analyzed during this study are included in this published article.

\section{Disclosures}

The authors have no significant conflicts of interest with any companies or organization whose products or services may be discussed in this article.

\section{Authors' contributions}

GK Participated in the design of the study, data collection, statistical analysis, interpretation of the results, writing and critical revision of the manuscript for important intellectual content and final approval of the manuscript submitted. MA Participated in the design of the study, data collection, interpretation of the results, writing and critical revision of the manuscript for important intellectual content and final approval of the manuscript submitted. MDF Participated in the data collection, interpretation of the results and critical revision of the manuscript for important intellectual content and final approval of the manuscript submitted. WD Participated in the data collection, interpretation of the results and critical revision of the manuscript for important intellectual content and final approval of the manuscript submitted. RAD Participated in the design of the study, interpretation of the results and critical revision of the manuscript for important intellectual content and final approval of the manuscript submitted. ART Participated in the design of the study, data collection, statistical analysis, interpretation of the results, writing and critical revision of the manuscript for important intellectual content and final approval of the manuscript submitted. ART is the guarantor of the paper, taking responsibility for the integrity of the work as a whole, from inception to published article.

\section{Ethics approval and consent to participate}

This study was approved by the Cleveland Clinic institutional review board (study number: 06-245 and 14-1069). Written informed consent was waived given the retrospective nature of the study.

\section{Competing interests}

Ghaleb Khirfan MD: The author has no significant conflicts of interest with any companies or organization whose products or services may be discussed in this article.

Mostafa K. Ahmed MD: The author has no significant conflicts of interest with any companies or organization whose products or services may be discussed in this article.

Michael D. Faulx MD: The author has no significant conflicts of interest with any companies or organization whose products or services may be discussed in this article.

Wael Dakkak MD: The author has no significant conflicts of interest with any companies or organization whose products or services may be discussed in this article.

Raed A. Dweik MD: The author has no significant conflicts of interest with any companies or organization whose products or services may be discussed in this article.

Adriano R. Tonelli MD: The author has no significant conflicts of interest with any companies or organization whose products or services may be discussed in this article.

\section{Publisher's Note}

Springer Nature remains neutral with regard to jurisdictional claims in published maps and institutional affiliations.

\section{Author details}

${ }^{1}$ Department of Pulmonary, Allergy and Critical Care Medicine, Respiratory Institute, Cleveland Clinic, 9500 Euclid Avenue A-90, Cleveland, $\mathrm{OH} 44195$, USA. ${ }^{2}$ Department of Chest Diseases, Faculty of Medicine, Assiut University, Assiut, Egypt. ${ }^{3}$ Department of Cardiovascular Medicine, Heart and Vascular Institute, Cleveland Clinic, Cleveland, $\mathrm{OH}$, USA. ${ }^{4}$ Department of Internal Medicine, John H. Stroger Jr. Hospital of Cook County, Chicago, IL, USA.
Received: 18 June 2018 Accepted: 20 December 2018

Published online: 08 January 2019

\section{References}

1. Tonelli AR, Arelli V, Minai OA, Newman J, Bair N, Heresi GA, Dweik RA. Causes and circumstances of death in pulmonary arterial hypertension. Am J Respir Crit Care Med. 2013;188:365-9.

2. Hoeper MM, Bogaard HJ, Condliffe R, Frantz R, Khanna D, Kurzyna M, Langleben D, Manes A, Satoh T, Torres F, et al. Definitions and diagnosis of pulmonary hypertension. J Am Coll Cardiol. 2013;62:D42-50.

3. Pabalan MJ, Nayak SP, Ryan RM, Kumar VH, Lakshminrusimha S. Methemoglobin to cumulative nitric oxide ratio and response to inhaled nitric oxide in PPHN. J Perinatol. 2009;29:698-701.

4. Morita T, Perrella MA, Lee ME, Kourembanas S. Smooth muscle cell-derived carbon monoxide is a regulator of vascular cGMP. Proc Natl Acad Sci U S A. 1995;92:1475-9.

5. Morita T, Mitsialis SA, Koike H, Liu Y, Kourembanas S. Carbon monoxide controls the proliferation of hypoxic vascular smooth muscle cells. J Bio Chem. 1997;272:32804-9.

6. Kourembanas S. Hypoxia and carbon monoxide in the vasculature. Antioxid Redox Signal. 2002;4:291-9.

7. Montellano PR. The mechanism of heme oxygenase. Curr Opin Chem Biol. 2000;4:221-7.

8. Meyer J, Prien T, Van Aken H, Bone HG, Waurick R, Theilmeier G, Booke M. Arterio-venous carboxyhemoglobin difference suggests carbon monoxide production by human lungs. Biochem Biophys Res Commun. 1998:244:230-2.

9. Scharte M, Bone HG, Van Aken H, Meyer J. Increased carbon monoxide in exhaled air of critically ill patients. Biochem Biophys Res Commun. 2000;267:423-6.

10. Dubuis E, Gautier M, Melin A, Rebocho M, Girardin C, Bonnet P, Vandier C. Chronic carbon monoxide enhanced IbTx-sensitive currents in rat resistance pulmonary artery smooth muscle cells. Am J Physiol Lung Cell Mol Physiol. 2002;283:L120-9.

11. Privat C, Lantoine F, Bedioui F, Millanvoye van Brussel E, Devynck J, Devynck MA. Nitric oxide production by endothelial cells: comparison of three methods of quantification. Life Sci. 1997:61:1193-202.

12. Giaid A, Saleh D. Reduced expression of endothelial nitric oxide synthase in the lungs of patients with pulmonary hypertension. N Engl J Med. 1995:333:214-21.

13. Johnson ML, Emhoff CA, Horning MA, Brooks GA. Transpulmonary lactate shuttle. Am J Physiol Regul Integr Comp Physiol. 2012;302:R143-9.

14. De Backer D, Creteur J, Zhang H, Norrenberg M, Vincent JL. Lactate production by the lungs in acute lung injury. Am J Respir Crit Care Med. 1997:156:1099-104.

15. Bendjelid K, Treggiari MM, Romand JA. Transpulmonary lactate gradient after hypothermic cardiopulmonary bypass. Intensive Care Med. 2004;30:817-21.

16. Wang TL, Hsu KL, Chiang FT, Tseng CD, Tseng YZ. Anaerobic metabolism in patients undergoing intra-aortic balloon counterpulsation for cardiogenic shock. J Formos Med Assoc. 1995;94:379-85.

17. Inoue T, Sakai Y, Morooka S, Hayashi T, Takayanagi K, Yamaguchi H, Takabatake $Y$. Venoarterial carbon dioxide tension gradient in acute heart failure. Cardiology. 1993:82:383-7.

18. Harris P, Bailey T, Bateman M, Fitzgerald MG, Gloster J, Harris EA, Donald KW Lactate, pyruvate, glucose, and free fatty acid in mixed venous and arterial blood. J Appl Physiol. 1963;18:933-6.

19. Williams WH Jr, Olsen GN, Allen WG, Yergin BM. Use of blood gas values to estimate the source of blood withdrawn from a wedged flow-directed catheter in critically ill patients. Crit Care Med. 1982;10:636-40.

20. Brewster $\mathrm{H}, \mathrm{Mcll}$ roy MB. Blood gas tensions and $\mathrm{pH}$ of pulmonary "wedge" samples in patients with heart disease. J Appl Physiol. 1973;34:413-6.

21. Safian RD, Come SE, Kadin M, Lorell BH. Use of pulmonary capillary wedge aspirates for the antemortem diagnosis of pulmonary microvascular tumor. Catheter Cardiovasc Diagn. 1989;17:112-5.

22. Tonelli AR, Mubarak KK, Li N, Carrie R, Alnuaimat H. Effect of balloon inflation volume on pulmonary artery occlusion pressure in patients with and without pulmonary hypertension. Chest. 2011;139:115-21.

23. Simonneau G, Gatzoulis MA, Adatia I, Celermajer D, Denton C, Ghofrani A, Gomez Sanchez MA, Krishna Kumar R, Landzberg M, Machado RF, et al. Updated clinical classification of pulmonary hypertension. J Am Coll Cardiol. 2013;62:D34-41.

24. Tonelli AR, Alnuaimat H, Mubarak K. Pulmonary vasodilator testing and use of calcium channel blockers in pulmonary arterial hypertension. Respir Med. 2010;104:481-96. 
25. West JB, Dollery $\mathrm{CT}$. Distribution of blood flow and the pressure-flow relations of the whole lung. J Appl Physiol. 1965;20:175-83.

26. Ahmed M, Dweik RA, Tonelli AR. What is the best approach to a high systolic pulmonary artery pressure on echocardiography? Cleve Clin J Med. 2016;83:256-60.

27. Macintyre N, Crapo RO, Viegi G, Johnson DC, van der Grinten CP, Brusasco V, Burgos F, Casaburi R, Coates A, Enright P, et al. Standardisation of the single-breath determination of carbon monoxide uptake in the lung. Eur Respir J. 2005;26:720-35.

28. Hoeper M, Pletz M, Golpon H, Welte T. Prognostic value of blood gas analyses in patients with idiopathic pulmonary arterial hypertension. Eur Respir J. 2007;29:944-50.

29. Rich S, Dantzker DR, Ayres SM, Bergofsky EH, Brundage BH, Detre KM, Fishman AP, Goldring RM, Groves BM, Koerner SK, et al. Primary pulmonary hypertension. A national prospective study. Ann Intern Med. 1987:107:216-23.

30. Douzinas EE, Tsidemiadou PD, Pitaridis MT, Andrianakis I, Bobota-Chloraki A, Katsouyanni K, Sfyras D, Malagari K, Roussos C. The regional production of cytokines and lactate in sepsis-related multiple organ failure. Am J Respir Crit Care Med. 1997;155:53-9.

31. Brown SD, Clark C, Gutierrez G. Pulmonary lactate release in patients with sepsis and the adult respiratory distress syndrome. J Crit Care. 1996;1 1:2-8.

32. Zapol WM, Rimar S, Gillis N, Marletta M, Bosken CH. Nitric oxide and the lung. Am J Respir Crit Care Med. 1994;149:1375-80.

33. Gow AJ, Luchsinger BP, Pawloski JR, Singel DJ, Stamler JS. The oxyhemoglobin reaction of nitric oxide. Proc Natl Acad Sci U S A. 1999;96:9027-32.

34. Naples R, Laskowski D, McCarthy K, Mattox E, Comhair SA, Erzurum SC. Carboxyhemoglobin and methemoglobin in asthma. Lung. 2015;193:183-7.

35. Tenhunen R, Marver HS, Schmid R. Microsomal heme oxygenase. Characterization of the enzyme. J Biol Chem. 1969;244:6388-94.

36. Furchgott RF, Jothianandan D. Endothelium-dependent and -independent vasodilation involving cyclic GMP: relaxation induced by nitric oxide, carbon monoxide and light. Blood Vessels. 1991;28:52-61.

37. Otterbein LE, Bach FH, Alam J, Soares M, Tao Lu H, Wysk M, Davis RJ, Flavell RA, Choi AM. Carbon monoxide has anti-inflammatory effects involving the mitogen-activated protein kinase pathway. Nat Med. 2000;6:422-8.

38. Liang OD, Mitsialis SA, Chang MS, Vergadi E, Lee C, Aslam M, Fernandez-Gonzalez A, Liu X, Baveja R, Kourembanas S. Mesenchymal stromal cells expressing heme oxygenase-1 reverse pulmonary hypertension. Stem Cells. 2011;29:99-107.

39. Christou H, Morita T, Hsieh CM, Koike H, Arkonac B, Perrella MA, Kourembanas S. Prevention of hypoxia-induced pulmonary hypertension by enhancement of endogenous heme oxygenase-1 in the rat. Circ Res. 2000;86:1224-9.

40. Yasuda H, Sasaki T, Yamaya M, Ebihara S, Maruyama M, Kanda A, Sasaki H. Increased arteriovenous carboxyhemoglobin differences in patients with inflammatory pulmonary diseases. Chest. 2004;125:2160-8.

41. Sandoval J, Bauerle O, Palomar A, Gomez A, Martinez-Guerra ML, Beltran M, Guerrero ML. Survival in primary pulmonary hypertension. Validation of a prognostic equation. Circulation. 1994;89:1733-44.

42. Wensel R, Opitz CF, Anker SD, Winkler J, Hoffken G, Kleber FX, Sharma R, Hummel M, Hetzer R, Ewert R. Assessment of survival in patients with primary pulmonary hypertension: importance of cardiopulmonary exercise testing. Circulation. 2002;106:319-24.

43. Khirfan G, Naal T, Abuhalimeh B, Newman J, Heresi GA, Dweik RA, Tonelli. AR. Hypoxemia in patients with idiopathic or heritable pulmonary arterial hypertension. PLoS One. 2018;13:e0191869.

44. Wright JL, Levy RD, Churg A. Pulmonary hypertension in chronic obstructive pulmonary disease: current theories of pathogenesis and their implications for treatment. Thorax. 2005;60:605-9.

45. Wright JL, Churg A. Effect of long-term cigarette smoke exposure on pulmonary vascular structure and function in the Guinea pig. Exp Lung Res. 1991:17:997-1009.

46. Peinado VI, Pizarro S, Barbera JA. Pulmonary vascular involvement in COPD. Am J Respir Crit Care Med. 2008:134:808-14.

47. Ferrer E, Peinado VI, Diez M, Carrasco JL, Musri MM, Martinez A, RodriguezRoisin R, Barbera JA. Effects of cigarette smoke on endothelial function of pulmonary arteries in the Guinea pig. Respir Res. 2009;10:76

48. Barbera JA, Peinado VI, Santos S. Pulmonary hypertension in chronic obstructive pulmonary disease. Eur Respir J. 2003;21:892-905.

\section{Ready to submit your research? Choose BMC and benefit from:}

- fast, convenient online submission

- thorough peer review by experienced researchers in your field

- rapid publication on acceptance

- support for research data, including large and complex data types

- gold Open Access which fosters wider collaboration and increased citations

- maximum visibility for your research: over $100 \mathrm{M}$ website views per year

At BMC, research is always in progress.

Learn more biomedcentral.com/submissions 